\title{
Caracterização e incorporação de resíduos provenientes de Estação de Tratamento de Água em cerâmica argilosa
}

\author{
(Characterization and incorporation of wastes from Water \\ Treatment Plant into clayey ceramic)
}

\author{
J. P. D. Vitorino, S. N. Monteiro, C. M. F. Vieira \\ Laboratório de Materiais Avançados - LAMAV, Universidade Estadual do Norte Fluminense Darcy Ribeiro \\ UENF, Av. Alberto Lamego 2000, Campos dos Goytacazes, RJ 28013-602 \\ vieira@uenf.br
}

\begin{abstract}
Resumo
O objetivo deste trabalho é caracterizar e incorporar, em cerâmica argilosa, três tipos de resíduos provenientes das etapas de desarenação, decantação e de filtração de uma estação de tratamento de água - ETA. Os resíduos foram caracterizados por difração de raios $\mathrm{X}$, fluorescência de raios $\mathrm{X}$, análise termogravimétrica e térmica diferencial, microscopia eletrônica de varredura e técnicas de peneiramento e sedimentação. As propriedades físicas e mecânicas avaliadas das cerâmicas incorporadas com até $10 \%$ em peso de resíduos e queimadas a $700{ }^{\circ} \mathrm{C}$ foram retração linear, absorção de água e compressão diametral. Os resultados mostraram que os resíduos do decantador e do filtro possuem composição química e mineralógica semelhantes, formados por minerais argilosos, hidróxidos de alumínio e de ferro, mica e quartzo. O resíduo do desarenador é formado basicamente de quartzo com traços de mica e de caulinita. Os três tipos de resíduos apresentaram potencialidade para utilização em cerâmica vermelha. Entretanto, o resíduo arenoso do desarenador foi o tipo de resíduo que possibilitou benefícios diretos como a melhoria da trabalhabilidade da massa bem como redução da retração linear e da absorção de água da cerâmica queimada.
\end{abstract}

Palavras-chave: caracterização, areia, estação de tratamento de água, lodo, propriedades, resíduo.

\begin{abstract}
This work has for objective to characterize and to incorporate into a clayey body three types of wastes from the stage of sand collecting, decantation and filtration of a water treatment plant. The wastes were characterized by X-ray diffraction, X-ray fluorescence, thermogravimetric and differential thermal analyses as well as by sieving and sedimentation. The evaluated physical and mechanical properties of the ceramics, incorporated with up to $10 \mathrm{wt} . \%$ of wastes and fired at $700{ }^{\circ} \mathrm{C}$, were linear shrinkage, water absorption and diametrical compression. The results showed that the wastes from the decantation and filter have chemical and mineralogical compositions similar to clays, presenting clay minerals, aluminum and iron hydroxides, as well as mica and quartz. On the other hand, the waste from the sand collector is basically formed by quartz with traces of mica and kaolinite. The three types of wastes have potential to be incorporated into clayey ceramic. However, the sand waste from the sand collector in associate with direct benefits such as a better workability of the body as well as decrease of the fired ceramic linear shrinkage and water absorption.
\end{abstract}

Keywords: characterization, sand, water treatment plant, sludge, properties, waste.

\section{INTRODUÇÃO}

Resíduos sólidos são uma crescente preocupação mundial devido ao seu grande volume e, também, a dificuldade de sua destinação final. Estes resíduos podem gerar custos adicionais e sérios problemas ambientais quando depositados em locais como aterros sanitários ou lixões, causando a degradação do solo, contaminação tanto do lençol freático quanto de mananciais e, também, a contaminação do ar. A incorporação de resíduos de várias atividades em produtos cerâmicos argilosos é uma alternativa tecnológica que pode contribuir para a redução do impacto ambiental [13]. A etapa de queima do processamento da cerâmica pode promover a inertização de materiais potencialmente tóxicos por volatilização, transformação química e estabilização na fase vítrea que se forma pela participação de alumino silicatos e fundentes na massa cerâmica. Os resíduos podem ainda melhorar o processamento cerâmico, a qualidade da cerâmica e, ainda, contribuir para a redução do gasto energético na etapa de queima. Quando incorporados em quantidades significativas, contribuem para a redução do consumo de argilas, recurso natural não-renovável.

Um dos resíduos que apresentam potencial de reciclagem em cerâmica vermelha são os lodos gerados em Estações de Tratamento de Água - ETA [4-8]. O constante aumento na produção de água tratada para o consumo humano vem 
provocando um crescimento do montante de resíduos gerados pelo tratamento. $\mathrm{Na}$ maioria das estações, os resíduos provenientes das etapas de decantação e filtração, quase sempre são descartados em rios, lagos ou outro reservatório d'água, ou seja, geralmente na própria fonte de captação. Esta prática pode ocasionar assoreamento no local de despejo. Além disso, para remoção do lodo normalmente utiliza-se água tratada que, em seguida, é descartada juntamente com o lodo, o que diminui a produtividade da estação de tratamento. Com a implantação de um sistema de centrifugação para reaproveitamento da água de lavagem e obtenção do lodo "seco", abre-se a possibilidade de que a destinação ambientalmente correta a ser adotada para o lodo seja a incorporação em cerâmica vermelha. Além disso, estes resíduos já estão sendo vistos pelos órgãos ambientais como resíduos industriais e com isso, necessitam de uma destinação final adequada à determinação legal. A constituição dos lodos de ETA é basicamente de partículas argilosas, siltosas, arenosas e, também, de matéria orgânica, que são materiais encontrados nas argilas que se constituem nas principais matérias-primas para a cerâmica vermelha [48]. Estes trabalhos indicam que a incorporação de lodos de ETA deve ser realizada em pequenas quantidades para não prejudicar as propriedades físicas e mecânicas da cerâmica queimada. Foi observado ainda que, por meio de ensaio de solubilização, a cerâmica em geral inertiza os constituintes tóxicos e perigosos eventualmente presentes no lodo [7]. Além do lodo de decantador, o tipo de resíduo de ETA mais investigado na literatura, este trabalho avalia outros tipos de resíduos de ETA, disponibilizando assim novas informações a respeito de resíduos de ETA e sua reciclagem em massa de cerâmica vermelha.

\section{MATERIAL E MÉTODOS}

Foram utilizados os seguintes materiais: massa de cerâmica vermelha e resíduos de três etapas do processamento de uma ETA. A massa de cerâmica vermelha é proveniente de uma indústria cerâmica localizada no município de Campos dos Goytacazes, RJ, sendo constituída da mistura de duas argilas cauliníticas [9]. Os resíduos são provenientes do processo de tratamento de água da ETA da empresa Águas do Paraíba S/A localizada também no município de Campos dos Goytacazes e foram coletados nas etapas de desarenação, decantação e filtração.

Os resíduos foram caracterizados por meio de difração de raios X (DRX), fluorescência de raios X (FRX), análise térmica diferencial e termogravimétrica (ATD/TG), microscopia eletrônica de varredura (MEV), peneiramento e sedimentação. Para o ensaio de DRX foram utilizadas amostras em forma de pó em um difratômetro Seifert URD 65 com radiação $k \alpha$ do $\mathrm{Cu}(\lambda=1,54060 \AA)$ para $2 \theta$ variando de $5^{\circ}$ a $60^{\circ}$ com varredura de $0,02^{\circ} \%$ s. As interpretações qualitativas de espectro foram efetuadas por comparação com padrões contidos no banco de dados PDF02 [10]

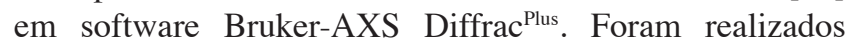
ensaios de ATD/TG dos resíduos num instrumento de análise térmica simultânea TA Instruments SDT 2960. As amostras foram aquecidas de $25 \mathrm{a} 1000{ }^{\circ} \mathrm{C}$ à taxa de $10^{\circ} \mathrm{C} /$ min e resfriadas naturalmente. A composição química das matérias-primas foi determinada por FRX em equipamento Philips PW 2400. Para a determinação do carbono orgânico utilizou-se o método calorimétrico, sendo as amostras dos resíduos digeridas em uma solução de dicromato de potássio e ácido sulfúrico concentrado, aquecida por $1 \mathrm{~h}$ a $150{ }^{\circ} \mathrm{C}$, resfriada, em seguida adicionou-se cloreto de bário para facilitar a decantação. A leitura da amostra foi feita em espectrofotômetro Spekol UV-VIS 3.0. A morfologia das partículas dos resíduos, metalizadas com ouro, foi analisada por MEV em um microscópio Jeol JSM 6460 LV com sistema de energia dispersiva (EDS). A distribuição de tamanho de partícula dos resíduos foi determinada pela combinação das técnicas de peneiramento e sedimentação de acordo com norma técnica [11].

Foram realizadas incorporações dos três tipos de resíduos na massa cerâmica argilosa nas quantidades de $0,3,5,7$ e $10 \%$ em peso. A homogeneização das matérias-primas foi conduzida em galga misturadora de pista lisa.

Para a determinação das propriedades físicas e mecânicas, tais como retração linear, absorção de água e compressão diametral, foram confeccionados corpos-de-prova cilíndricos (diâmetro 20,1 mm) por prensagem uniaxial a $18 \mathrm{MPa}$. Os corpos-de-prova foram, então, queimados em forno de laboratório tipo mufla com taxa de aquecimento $2^{\circ} \mathrm{C} / \mathrm{min}$, sendo a temperatura máxima $700{ }^{\circ} \mathrm{C}$. O resfriamento foi realizado desligando-se o forno.

\section{RESULTADOS E DISCUSSÃO}

Na Fig. 1 encontram-se apresentados os difratogramas de raios $\mathrm{X}$ dos resíduos. O resíduo do desarenador é composto de quartzo, mica e caulinita. Os lodos do decantador e do filtro são constituídos, basicamente, por caulinita, quartzo, mica, gibsita, goetita, lepdocrocita e montmorilonita. Os resultados revelam que a composição dos resíduos de lodo das etapas de decantação e de filtragem da ETA é similar às argilas, com minerais argilosos e impurezas de quartzo, hidróxidos e mineral micáceo. A areia de quartzo do desarenador é um material eventualmente utilizado na composição de massa de cerâmica vermelha e se constitui como a principal impureza presente nas argilas.

Na Fig. 2 estão mostradas as curvas de análise térmica dos resíduos. Com relação aos resíduos de lodo, tanto do decantador quanto do filtro, existe uma similaridade muito significativa no comportamento térmico. Isto é devido à semelhança na composição mineralógica. Os três resíduos apresentaram um pico endotérmico em temperaturas inferiores a $70{ }^{\circ} \mathrm{C}$. Este pico está associado, basicamente, à perda de água higroscópica. Eventualmente, algum tipo de matéria orgânica também pode estar sendo eliminada nesta faixa de temperatura. Com o aumento da temperatura, o resíduo de desarenador apresenta um pico endotérmico a $254,7{ }^{\circ} \mathrm{C}$, que está associado à eliminação de água de composição dos hidróxidos de $\mathrm{Al}$ e de Fe. Embora estes 
hidróxidos não tenham sido identificados por difração de raios X, Fig. 1, devido à pequena quantidade presente na areia do desarenador ou à sobreposição de picos de difração,
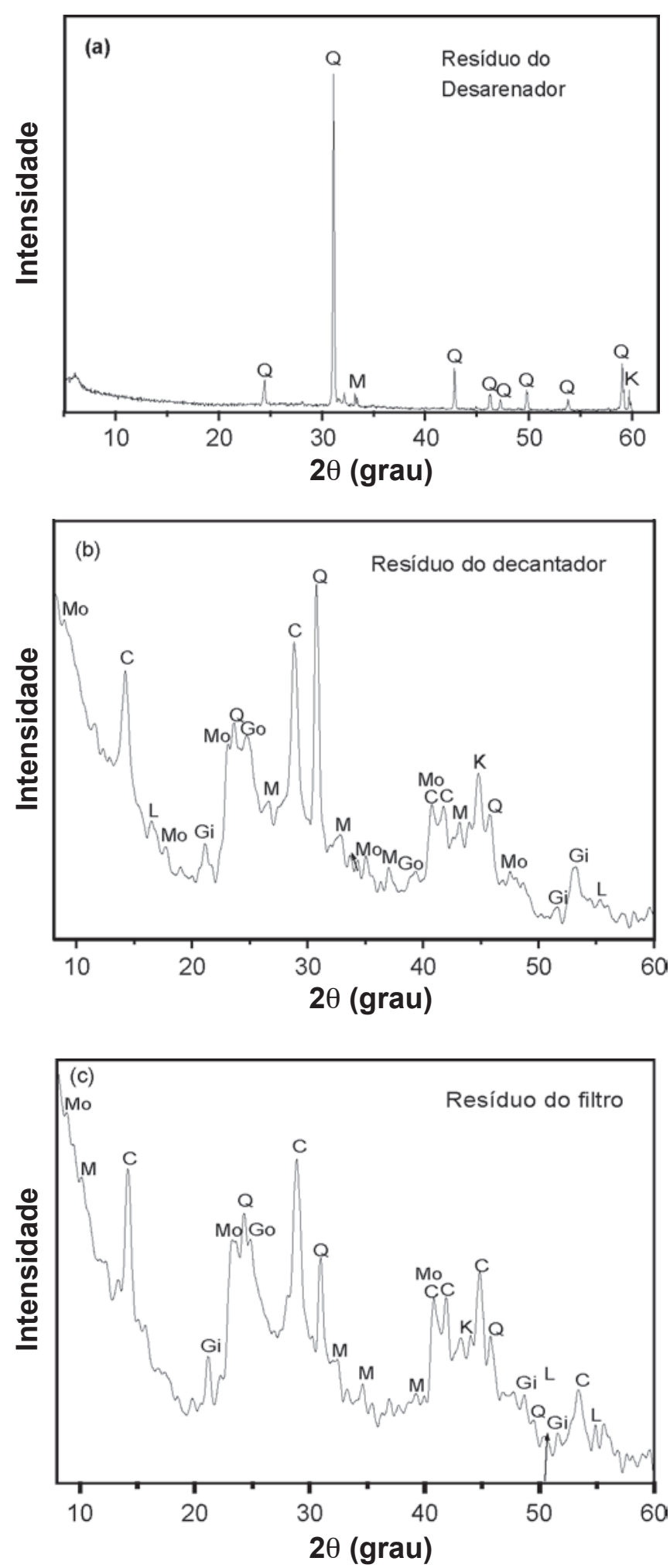

Figura 1: Difratogramas de raios $\mathrm{X}$ dos resíduos; caulinita - C; gibsita - GI; goetita - Go; lepdocrocita - L; mica - M; montmorilonita - Mo; quartzo - Q.

[Figure 1: X-ray diffraction paptterns of the wastes.]
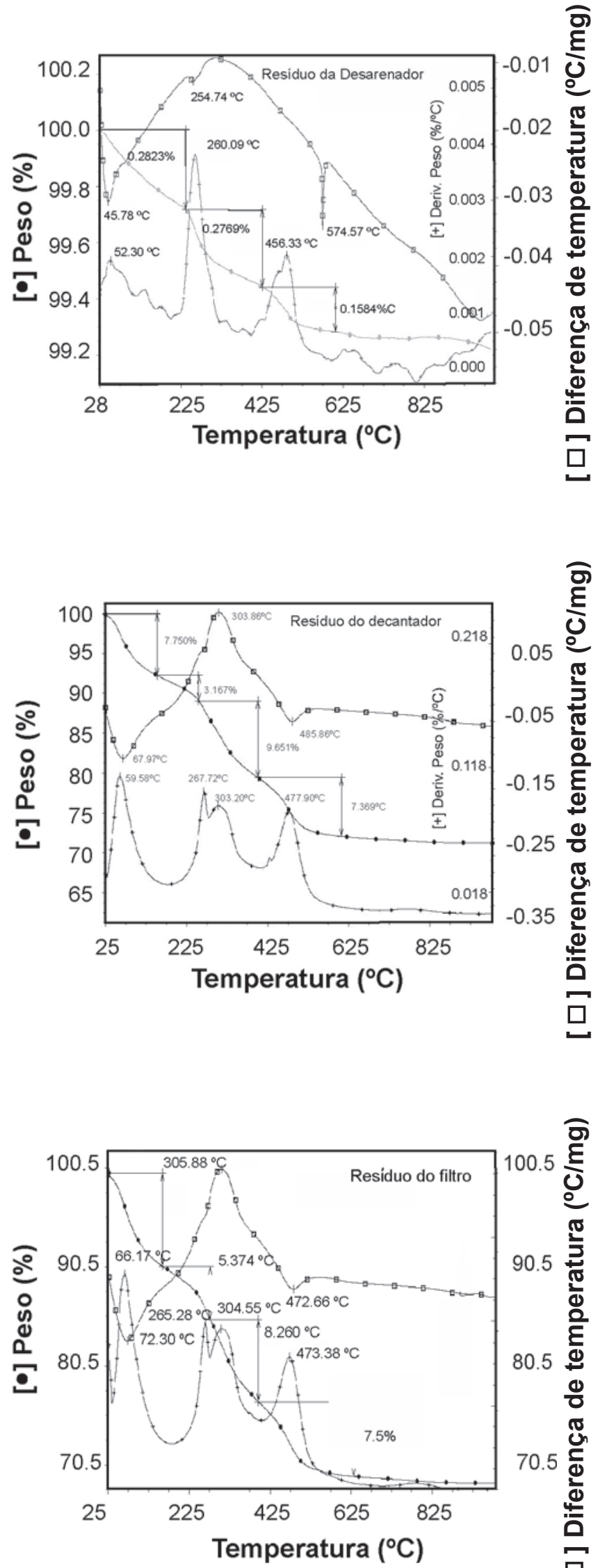

100.5

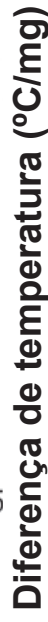

Figura 2: Curvas de ATD/TG/DTG dos resíduos. [Figure 2: DTA/TG/DTG curves of the wastes.] 
Tabela I - Composição química dos resíduos (\%) em peso.

[Table I - Chemical composition of the wastes (wt.\%).]

\begin{tabular}{ccccccccccc}
\hline Resíduos & $\mathrm{SiO}_{2}$ & $\mathrm{Al}_{2} \mathrm{O}_{3}$ & $\mathrm{Fe}_{2} \mathrm{O}_{3}$ & $\mathrm{P}_{2} \mathrm{O}_{5}$ & $\mathrm{~K}_{2} \mathrm{O}$ & $\mathrm{CaO}$ & $\mathrm{TiO}_{2}$ & $\mathrm{MnO}_{2}$ & $\mathrm{PF}$ & $\mathrm{MO}$ \\
\hline Resíduo do desarenador & 89,64 & 4,85 & 1,70 & - & 1,27 & - & - & - & 0,60 & 0,17 \\
Resíduo do decantador & 41,12 & 38,31 & 16,34 & 0,64 & 0,89 & 0,25 & 1,16 & 0,28 & 28,0 & 8,64 \\
Resíduo do filtro & 36,62 & 41,46 & 17,96 & 0,83 & 0,71 & 0,19 & 1,02 & 0,21 & 32,0 & 9,07 \\
\hline
\end{tabular}

as curvas de ATD/TG mostram claramente sua presença. Além disso, os demais resíduos, lodo do decantador e lodo do filtro, apresentaram estes hidróxidos em sua composição mineralógica, conforme mostrado na Fig. 1. Para os resíduos em forma de lodo ocorre, ao redor de $304{ }^{\circ} \mathrm{C}$, uma reação exotérmica associada à oxidação de matéria orgânica. Possivelmente, o pico endotérmico de eliminação de água de hidróxidos tenha sido encoberto por esta reação. Os dois tipos de lodo, do filtro e do decantador, apresentaram, ainda, uma outra reação endotérmica associada à eliminação de água de constituição da caulinita, que ocorre por volta de 482 e $485^{\circ} \mathrm{C}$, respectivamente [12]. Tanto a oxidação de matéria orgânica quanto a eliminação de água da caulinita são responsáveis por uma significativa perda de massa nos resíduos de lodo. Esta perda de massa, embora contribua com aporte adicional de calor devido à combustão de matéria orgânica, também aumenta a porosidade da cerâmica. Esta característica dos lodos de ETA é que geralmente leva à um aumento da absorção de água e à queda da resistência mecânica da cerâmica argilosa incorporada. Finalmente, observa-se na Fig. 2 um último pico endotérmico à $574,6{ }^{\circ} \mathrm{C}$ no resíduo do desarenador. Esta reação corresponde à transformação alotrópica do quartzo- $\alpha$ para quartzo- $\beta$ e que pode acarretar no aparecimento de trincas na cerâmica contribuindo para a redução da resistência mecânica.

Na Tabela I está apresentada a composição química dos resíduos. O resíduo de desarenador é constituído basicamente de $\mathrm{SiO}_{2}$, associada, sobretudo, às partículas de quartzo.

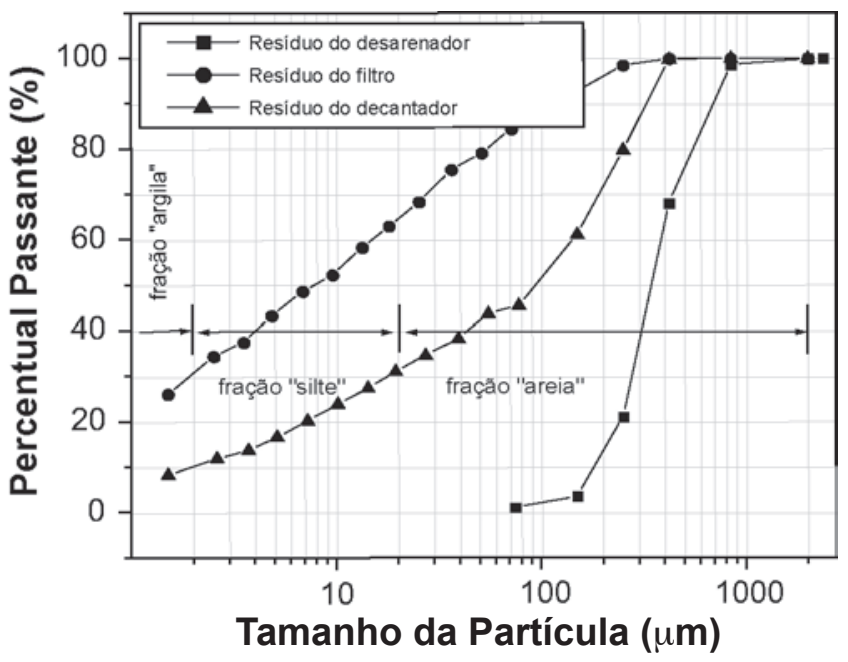

Figura 3: Distribuição de tamanho de partículas dos resíduos. [Figure 3: Particle size distribution of the wastes.]
$\mathrm{Al}_{2} \mathrm{O}_{3}, \mathrm{Fe}_{2} \mathrm{O}_{3}$ e $\mathrm{K}_{2} \mathrm{O}$ estão associados com impurezas como mica muscovita, caulinita e hidróxidos. Os dois outros resíduos possuem composição química muito similar, na qual predominam $\mathrm{SiO}_{2}$ e $\mathrm{Al}_{2} \mathrm{O}_{3}$. O resíduo do decantador apresenta uma quantidade maior de $\mathrm{SiO}_{2}$ devido à maior presença de areia fina, conforme será mostrado na curva de distribuição de tamanho de partícula. O resíduo do filtro possui uma maior quantidade de $\mathrm{Al}_{2} \mathrm{O}_{3}$, a qual está associada, sobretudo, à caulinita. Este mineral apresenta tamanho de partícula extremamente pequeno o que dificulta sua decantação. Desta forma, estas partículas são retidas com mais facilidade na etapa de filtragem. A maior porcentagem de perda ao fogo dos lodos, tanto de decantador como de filtro, indica uma elevada fração de minerais argilosos como a caulinita e, também, uma maior quantidade de matéria orgânica e de hidróxidos.

Na Fig. 3 está mostrada a distribuição de tamanho de partículas dos resíduos. O resíduo do desarenador apresenta uma distribuição de tamanho de partículas mais grosseira totalmente concentrada na fração "areia" que varia de 20 a $2000 \mu \mathrm{m}$. Para a incorporação em cerâmica vermelha este resíduo pode ser diretamente utilizado, sem a necessidade de peneiramento ou cominuição, uma vez que a abertura dos laminadores geralmente é maior que $2000 \mu \mathrm{m}$. Os resíduos na forma de lodo, provenientes do decantador e do filtro, apresentam um tamanho médio de partículas bem inferior ao resíduo do desarenador. Os teores das frações "argila", "silte" e "areia" para os lodos do decantador e do filtro foram 10,21 e $69 \%$ e 30,35 e $35 \%$, respectivamente. O lodo do filtro apresentou um tamanho médio de partículas inferior ao lodo do decantador, por passar pela etapa de filtragem que tem como objetivo reter as partículas menores que não decantaram.

Nas Figs. 4 a 6 encontram-se apresentadas as micrografias obtidas por MEV dos resíduos na forma de pó com mapeamento por EDS dos elementos Al, Si e Fe. Na Fig. 4, correspondente ao resíduo do desarenador, foram observadas partículas com predomínio de Si. Estas partículas estão associadas ao quartzo, conforme mostrado na Fig. 1. Os resíduos do decantador e do filtro apresentaram predomínio de $\mathrm{Al}$ e $\mathrm{Si}$, os quais estão combinados formando a estrutura dos aluminossilicatos como a caulinita, predominante, bem como a mica. Além disso, uma parte do $\mathrm{Al}$ está na forma de hidróxido, a gibsita, conforme indicado na Fig. 1.

Na Fig. 7 está apresentado um prognóstico de extrusão [13] por meio do índice de plasticidade e do limite de plasticidade das formulações com 0 e $10 \%$, em peso, 

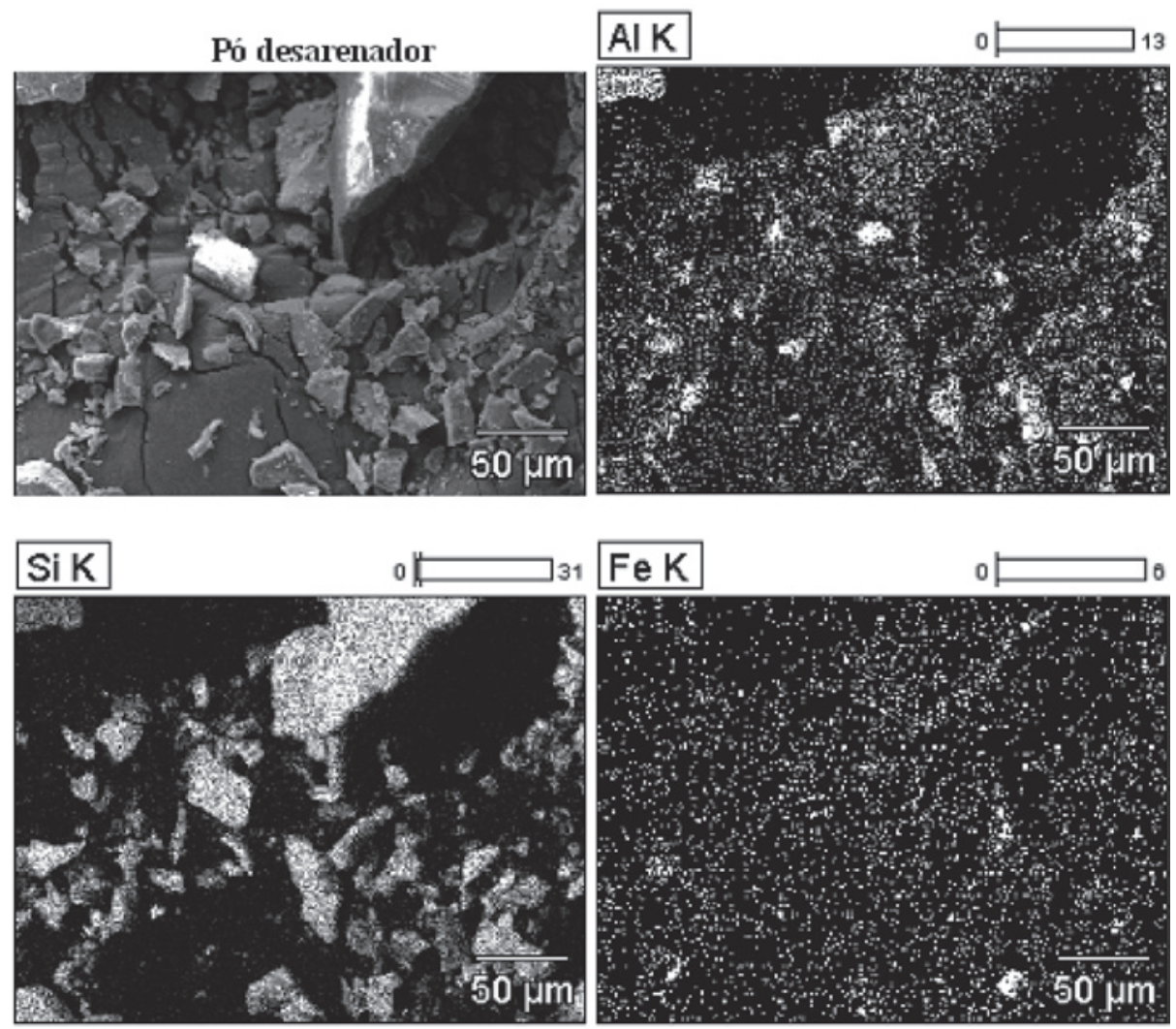

Figura 4: Micrografias obtidas por MEV do resíduo do desarenador.

[Figure 4: SEM micrographs of the waste from the sand collector.]
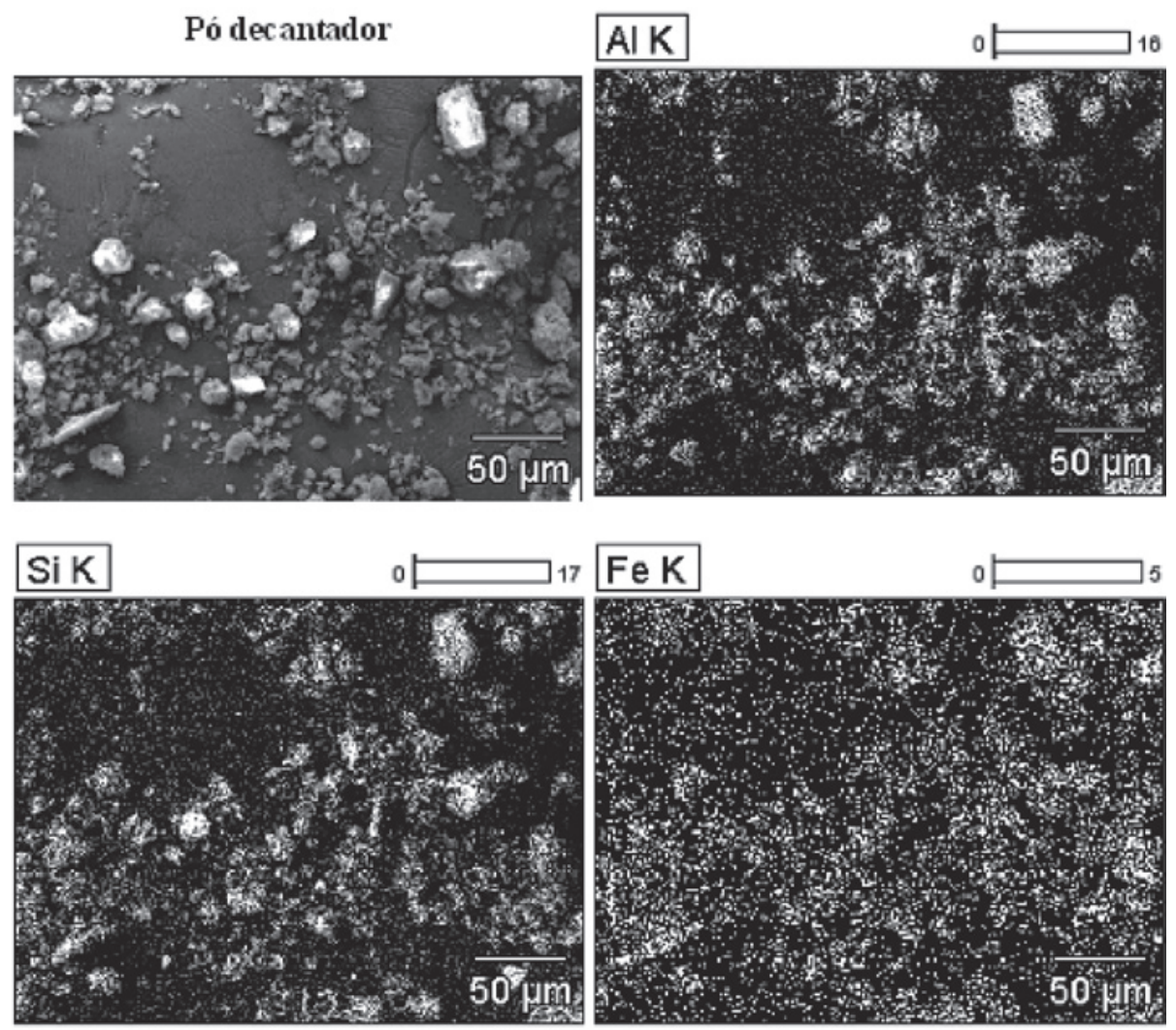

Figura 5: Micrografias obtidas por MEV do resíduo do decantador. [Figure 5: SEM micrographs of the waste from the decantator.] 
Pó Filtro

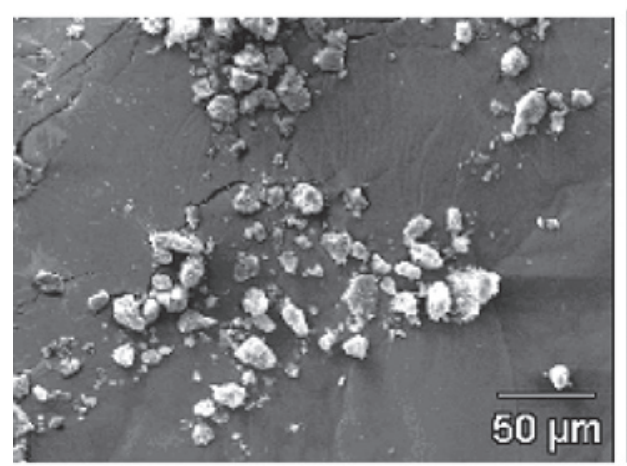

\section{Si K}

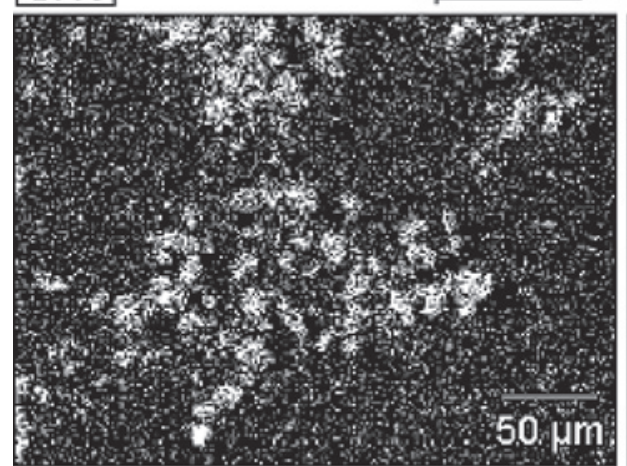

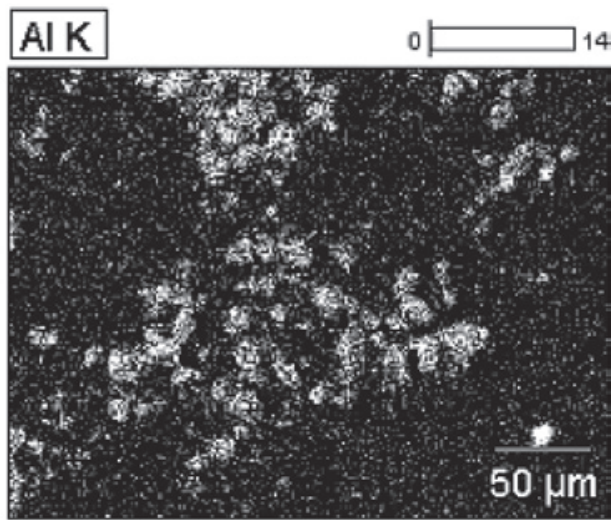
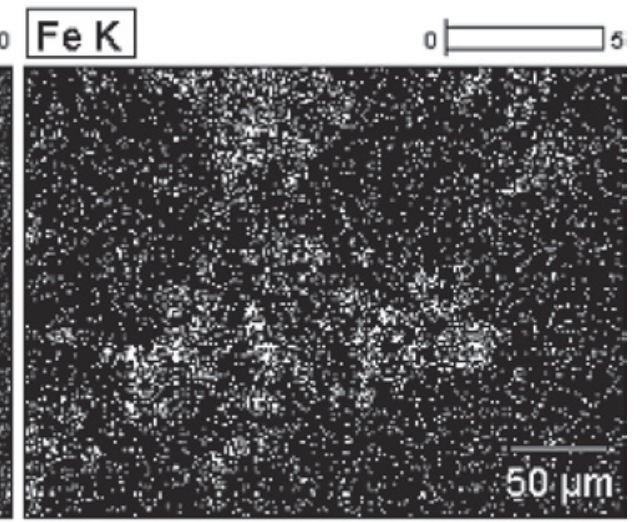

Figura 6: Micrografias obtidas por MEV do resíduo do filtro.

[Figure 6: SEM micrographs of the waste from the filter.]

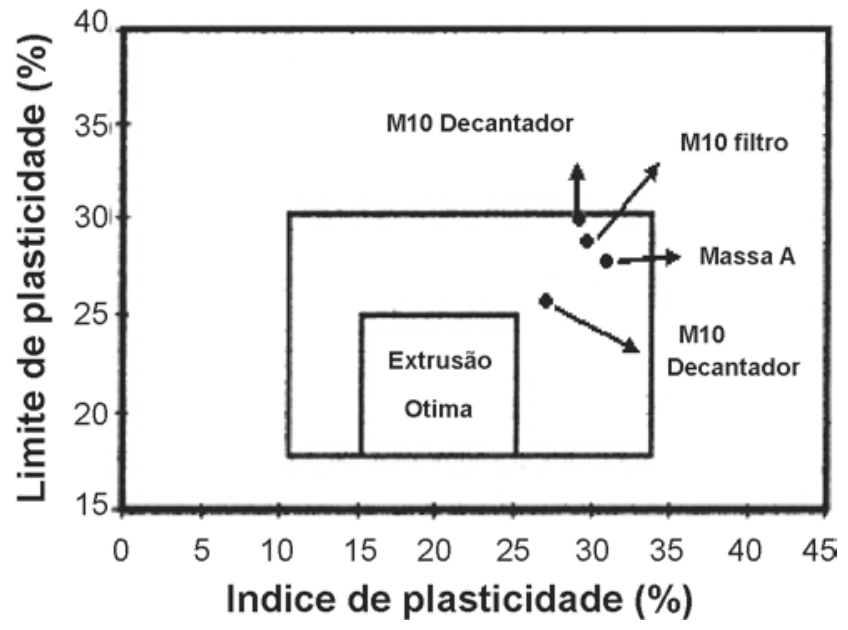

Figura 7: Prognóstico de extrusão pelos limites de Atterberg [13]. $(\bullet)$ Localização das composições.

[Figure 7: Extrusion prognosis through Atterberg limits [13]. (•) Localization of the compositions.]

de resíduos incorporados na massa argilosa. Observa-se que a massa cerâmica argilosa (massa A) está localizada dentro da região de extrusão aceitável. A adição de $10 \%$ em peso dos resíduos do decantador (M10Decantador) e do filtro (M10Filtro) à massa argilosa acarretou um ligeiro aumento no limite de plasticidade e pequena redução no índice de plasticidade da massa argilosa. Entretanto, estas composições continuam se localizando muito próximas uma das outras e distantes da região de extrusão ótima. Por outro lado, o resíduo de desarenador proporcionou uma redução mais acentuada tanto do limite de plasticidade quanto do índice de plasticidade da massa argilosa, possibilitando um deslocamento em direção à região de extrusão ótima. Este resultado é devido à composição mineralógica dos resíduos. Enquanto os lodos têm constituição mineralógica similar às argilas, o resíduo do desarenador é constituído, basicamente, de areia de quartzo que atua como desplastificante, contribuindo assim para a redução da plasticidade da massa argilosa.

Na Fig. 8 está mostrado o comportamento da absorção de água das cerâmicas queimadas em função da quantidade de resíduos incorporados. Os diferentes resíduos levaram a resultados distintos. O resíduo do desarenador reduziu a absorção de água da cerâmica argilosa, principalmente, em incorporações maiores. Isso se deve à grande quantidade de quartzo presente no resíduo, o qual melhora o grau de empacotamento e reduz a perda de massa durante a queima da cerâmica argilosa. Por outro lado, os resíduos do decantador e do filtro aumentaram a absorção de água, ou seja, aumentaram a porosidade aberta da cerâmica quando incorporados em quantidades acima de $3 \%$ em peso. Isto é devido à elevada perda de massa durante a queima, que ocorre em função da combustão de matéria orgânica, eliminação de água de constituição da caulinita e dos hidróxidos.

A Fig. 9 mostra o comportamento da retração linear 


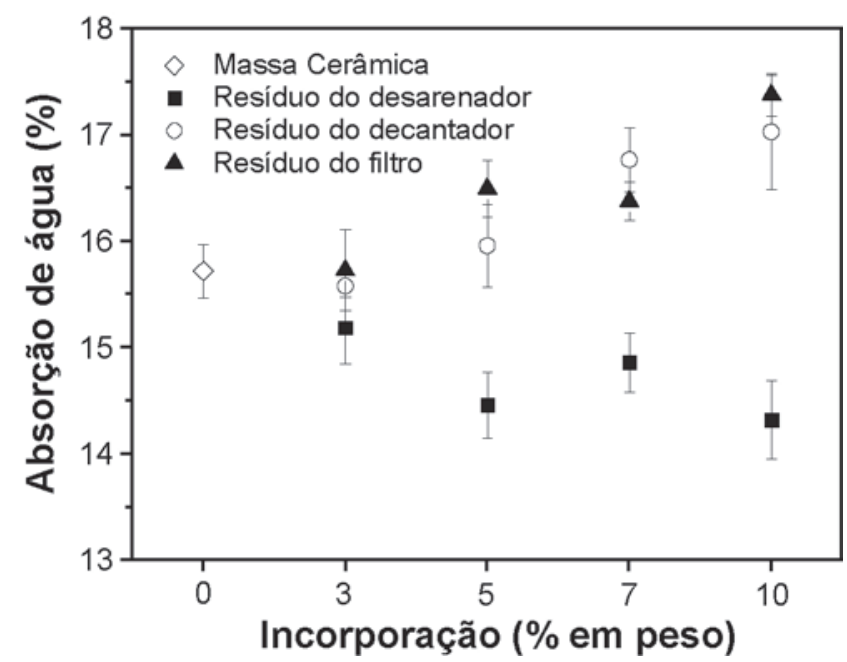

Figura 8: Absorção de água das cerâmicas queimadas. [Figure 8: Water absorption of the fired ceramics.]

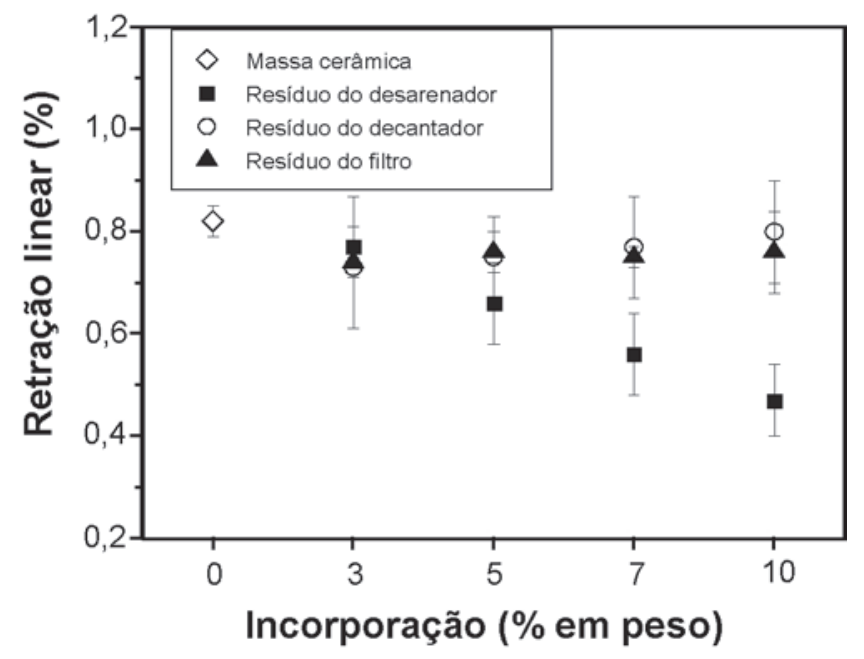

Figura 9: Retração linear das cerâmicas queimadas.

[Figure 9: Linear shrinkage of the fired ceramics.]

das cerâmicas queimadas em função da quantidade de resíduos incorporados. O resíduo de desarenador reduziu consideravelmente a retração linear da cerâmica argilosa. Este comportamento se deve ao quartzo durante o processo de queima, comportando-se como material inerte. Os resíduos do decantador e do filtro praticamente não alteraram a retração linear da cerâmica argilosa.

A Fig. 10 mostra o comportamento da compressão diametral das cerâmicas queimadas em função da quantidade de resíduos incorporados. Estatisticamente, devido aos valores relativamente elevados do desvio-padrão, não ocorreu variação significativa da compressão diametral da cerâmica argilosa com os resíduos incorporados. Por outro lado, considerando os valores médios, pode-se afirmar que há uma tendência de redução da compressão diametral da cerâmica argilosa com o aumento da quantidade de resíduos incorporados. Para o resíduo do desarenador isto ocorre devido à transformação alotrópica do quartzo, acarretando

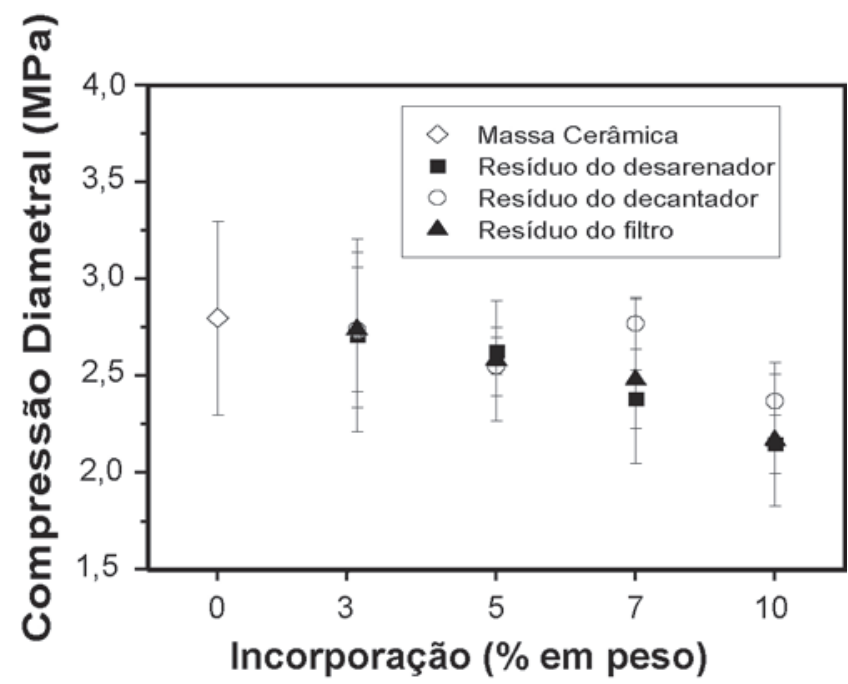

Figura 10: Compressão diametral das cerâmicas queimadas. [Figure 10: Diametrical compression of the fired ceramics.]

o aparecimento de trincas. Os resíduos do decantador e do filtro reduzem a resistência mecânica da cerâmica argilosa em função da elevada perda de massa que proporcionam durante a queima, acarretando maior porosidade na cerâmica.

\section{CONCLUSÕES}

$\mathrm{O}$ resíduo do desarenador possui alto teor de $\mathrm{SiO}_{2}$, associado, sobretudo, às partículas de quartzo. Embora sua distribuição de tamanho de partículas seja a mais larga dentre os resíduos investigados, ainda está compatível com o processamento de cerâmica vermelha. Os resíduos do decantador e do filtro apresentaram pequeno tamanho médio de partículas e, também, uma constituição mineralógica similar a das argilas, com predomínio de $\mathrm{SiO}_{2}$ e $\mathrm{Al}_{2} \mathrm{O}_{3}$. Estes resíduos revelaram um valor elevado de perda ao fogo, associado à perda de água de hidróxidos, combustão de matéria orgânica e eliminação de água de constituição da caulinita. O resíduo do desarenador atuou como desplastificante, sendo benéfico à plasticidade/ trabalhabilidade da cerâmica argilosa. Em relação às propriedades de queima, este resíduo reduziu a absorção de água e a retração linear da cerâmica. Por outro lado, mostrou, também, uma tendência à redução da resistência mecânica da cerâmica. Os resíduos do decantador e do filtro praticamente não alteraram a plasticidade/ trabalhabilidade da cerâmica argilosa. Em relação às propriedades de queima, aumentaram a absorção de água e reduziram a resistência mecânica da cerâmica. Os resultados indicam que o resíduo do desarenador apresenta maior potencial para ser incorporado em cerâmica argilosa. A maior restrição está relacionada à redução da resistência mecânica da cerâmica. Desta forma, deve-se incorporar quantidades que possibilitem à cerâmica alcançar os valores estipulados por norma para determinado tipo de produto. Os resíduos do decantador e do filtro podem 
ser incorporados em pequenas quantidades em cerâmica argilosa para uma destinação ambientalmente correta dos mesmos. A quantidade de matéria orgânica, ao redor de $9 \%$ em peso, não deve trazer economia significativa de energia durante a etapa de queima. Por outro lado, lodos de ETA com maior carga orgânica podem contribuir para a redução do gasto energético da cerâmica durante a etapa de queima. Além disso, devido ao elevado teor de água destes resíduos, deve-se realizar uma etapa de desaguamento e posterior filtro-prensagem para seu transporte às cerâmicas.

\section{AGRADECIMENTOS}

À empresa Águas do Paraíba S/A pelo fornecimento dos resíduos e ao CNPq pela concessão de bolsa de IC.

\section{REFERÊNCIAS}

[1] F. Raupp-Pereira, D. Hotza, A. M. Segadães, J. A. Labrincha, Ceram. Int. 32 (2006) 173.

[2] M. Dondi, M. Masigli, B. Fabbri, Tile \& Brick Int. 13, 3 (1997) 218.

[3] M. Dondi, M. Masigli, B. Fabbri, Tile \& Brick Int. 13,
4 (1997) 302.

[4] E. M. S Oliveira, S. Q. Machado, J. N. F. Holanda, Cerâmica 50, 316 (2004) 324.

[5] J. I. Margem, A. D. Ferreira, C. M. F. Vieira, S. N. Monteiro, Anais $49^{\circ}$ Cong. Bras. Cerâm., S. Pedro, SP (2005).

[6] O. K. Ueno, V. M. B. Leite, Anais 50 Cong. Bras. Cerâm., Blumenau, SC (2006).

[7] M. V. V. Ramires, I. S. dos Santos, C. S. Kazmierczak, Anais $49^{\circ}$ Cong. Bras. Cerâm., S. Pedro, SP (2005).

[8] L. C. C. Paixão, H. N. Yoshimura, D. C. R. Espinosa, J. A. S. Tenório, Cerâmica 54, 329 (2008) 63.

[9] S. N. Monteiro, C. M. F. Vieira, Tile \& Brick Int. 18, 3 (2002)152.

[10] The International Centre for Diffraction Data - ICDD, 2006, http://www.icdd.com. Acessado em 11/2007.

[11] Associação Brasileira de Normas Técnicas. Determinação da Análise Granulométrica de Solos. NBR 7181, Rio de Janeiro, RJ (1984).

[12] P. S. Santos, Ciência e Tecnologia das Argilas, 2. ${ }^{a}$ Ed., Editora Edgard Blücher Ltda., S. Paulo, SP (1989) 283

[13] M. Marsigli, M. Dondi, L'Industria dei Laterizi 46 (1997) 214.

(Rec. 30/05/2008, Rev. 12/08/2008, Ac. 22/08/2008) 